\title{
Research on the Computer Network Course under "Internet+" Environment
}

\author{
Shang Fengjun \\ College of Computer Science and Technology, Chongqing University of Posts and Telecommunications \\ Chongqing 400065
}

\begin{abstract}
In order to adapt to the "internet+" demand, we have optimized the contents about the computer network course. With respect to the teaching aspect, we have adopted hybrid hierarchy model, and constantly followed the advanced technology, to adapt to the constantly emerging and fast development characteristics of new technologies, new concepts and new applications of computer. With respect to the practical teaching aspect, we firstly utilize virtual simulation platform to verify from the practical aspect, and then use equipment to erect physical environment for partial students, conduct configuration and complete the experiment. Through the aforementioned two aspects of work, the contents of computer network course can adapt to the era development requirements, improve the manipulative ability of students, and achieve the course objective.
\end{abstract}

Keywords-Computer network; Practical teaching; Internet+; and teaching system

\section{INTRODUCTION}

Under the strategic background of national innovationdriven development, various new types of business, new modes and new products are constantly emerged, which have effectively stimulated the social creativity, and promoted the fast development of national economy. As the base for talent cultivation, the current education mode and education process in colleges cannot well meet the demand for innovative and entrepreneurial talents, and when implementing talent cultivation, the status of focusing on theory and knowledge while paying less attention to practical capacity is not fully dispensed. Along with the concept of "internet + " being put forward, and the close combination of unprecedented height and the innovation and entrepreneurship work of all fields, the society has a bigger and bigger demand for talents that can skillfully master the computer network technology, network construction, network application and development as well as network management, and people's enthusiasm for studying computer network technology is increased day by day. Thus, computer network has then become one of the core courses set for computer major in colleges [1], and the important position of computer network course in the entire discipline and the practical significance influencing social economy development have become the unquestioned fact.

\section{The OPtIMIZATION OF TEACHING CONTENTS}

As the core course of computer major, the optimization of computer network teaching contents are the basis and precondition of teaching reform. We adopt hybrid hierarchy model, which has absorbed the advantages of OSI reference model and TCP/IP reference models, and it is a compromised scheme [2], and includes 5 layers from top to bottom, i.e., the application layer, the transport layer, the network layer, the data link layer, and the physical layer, and finally, it has also increased the network safety contents. Being compared with OSI reference model, it is lack of the presentation layer and the session layer; the data link layer and physical layer have replaced the host and network layer of TCP/IP reference model [3]. Meanwhile, it has constantly followed the advanced technology, so as to adapt to the constantly emerging and fast development characteristics of new technologies, new concepts, and new applications for computer network, and with the fast development of network technology, we have fully integrated new technologies and the existing contents, for instance, in the introduction part, we have introduced the software definition and other new technologies of future network, and also introduced LiFi technology in the physical layer, and the quantum communication technology in the part of network safety. Therefore, it is requested to constantly revise the teaching program and replenish new teaching contents. After several years of modification, X.25, frame relay technology and other contents are deleted, and the broadband access technology and other contents are increased [4].

The several technologies combined method is adopted in the teaching process: (1) multi-media teaching method; use the multi-media courseware to show many knowledge points difficult to understand through the mode of audio-visual image. For instance, using PowerPoint and other courseware to fabricate animations of circuit switching, message switching, packet switching and other knowledge points, and this can largely improve the classroom efficiency. (2) Group discussion method. For some knowledge points with relatively strong practicability, firstly, let students conduct group discussion, and arouse students' active participation awareness. (3) Network teaching method; With respect to new network technology, let students actively utilize network to search and understand new technologies, and meanwhile, make a summary [5]. 


\section{The CREation of MultileVel and MUlti-Platform PRACTICAL TEACHING SYSTEM}

The objective of practical teaching is to optimize the students' quality structure, capacity structure and knowledge structure, and cultivate students' capacity for obtaining, applying and innovating knowledge [6]. The practical contents include two aspects: firstly, conducting from the aspect of principal verification and this mainly adopts virtual simulation platform for completion. In the second layer, equipment will be used to build physical environment for partial students, and then conduct configuration and complete the experiment.

The network system includes dada collection, transmission pipelines and applications. The network data collection includes the sensor data and the network data itself, and the transmission pipeline mainly completes the high-efficient and real-time transmission of data, and the application mainly completes smart data analysis, data integration and other tasks. The network laboratory firstly utilizes the protocol analysis system to conduct theoretical analysis verification for network protocol, and then uses the network principal platform to conduct the verification of network operation mechanism, and finally, utilizes the router and switch purchased thereby to erect actual network for verification and optimization. When the erected network transmits data, the data transmission shall be ensured to be safe and valid, so we have erected the network safety laboratory to reinforce the safe transmission of pipeline. The network application laboratory has erected the specific laboratory environment for students and teachers, and conducted secondary development for such environment, and generally, the innovative experiment contents are completed through the form of groups.

The network laboratory is mainly used to carry out the network laboratory of various major orientations, and its overall design shall meet the actual network engineering plan and construction demand, so the network system structure and application laboratory construction can be classified into four layers:

The first layer is the complete experiment type. There are five types of network experiment that can be conducted in network system structure and application laboratories: the network engineering experiment, the information safety experiment, the network protocol experiment, the converged communication experiment, and the network storage experiment. The network experiment can be classified into two types: the project-type network experiment oriented to daily teaching, and the comprehensive case experiment oriented to industrial application.

The second layer is the complete and real experimental environment. The actual construction of network has one characteristic, i.e., the complicity of network circuit and the diversity of protocol. To provide the best experimental effect for students and teachers, it is requested that the network laboratory shall erect these complicated environment as much as possible. Besides, it is requested that in the construction of network laboratory, there shall be financial backbone business network and large-scaled park networking mode and business concept; meanwhile, several types of LAN and WAN and the relevant network applications shall also be built.
The third layer is the complete experimental function. Build a public experimental center that can adapt to the technical development of computer network, and cover the teaching and experimental requirements of all layers, and provide a comprehensive experimental environment in the high-speed network construction, network management, network design, network safety, network application and other layers, and then through a series of verification type and comprehensive application type of experiments, students can master the experiment skills of computer network technology, and reinforce the understanding on the learned knowledge. Meanwhile, this has integrated data, voice and video through the most advanced technology.

The fourth layer is the complete laboratory layout. Complete the experiment from the edge access layer, the convergence layer, and the core switch layer to the entire network system of WAN in the laboratory. Meanwhile, in the construction process of laboratory, the unified management of laboratory equipment is fully considered, to realize the equal emphasis on the local use and remote opening of laboratories, and carry out remote teaching and remote laboratory operation.

Finally, a high-level network laboratory is established, and then various experimental systems are operated on the platform, making the experimental platform become the computer network technology experimental base and talent cultivation base meeting different layers of teaching demand.

Network engineering and networking experiment: the two layers and three layers of switch, router and other equipment based on the traditional network equipment manufacturer can erect the experimental environment of network engineering, cultivate the students' actual network equipment operation and configuration capacity, and meanwhile, realize the networking of different network structures, so as to cultivate the skills of students for being engaged in network engineer, system integration engineer, network plan engineer and other posts.

VoIP experiment: deploy one set of SIP server at the data center, to provide call registration, call router management and use for voice gateway, access router voice card, IAD equipment, and UCA; meanwhile, deploy one set of voice gateway in the data, and adopt E1 (R2/PRI/No. 7 signaling) interface to realize network intercommunication with PSTN.

IPTV network: deploy one set of IPTV server at the data center as the video source, and deploy set top box at the experimental area of students (PC installed with multicast client software can be used for replacement), and then start using three layers of multicast protocol in the data center, and core district (PIM-SM), and also start using the two layers of multicast protocol in the switch of the convergence area (IGMP SNOOPING), so as to realize the real-time receiving of IPTV Server video streaming for the set top box, and achieve the stimulation of the actually operated IPTV complete set of solution.

Wireless access network (3G+Wifi): insert 3G wireless card on multi-service router, and realize the interconnection with the $3 \mathrm{G}$ network of the operator, and internet access; currently, it can support all the three kinds of $3 \mathrm{G}$ standards 
(TD-SCDMA, WCDMA and CDMA2000), while the internal $\mathrm{PC}$ and printer as well as other office equipment are interconnected through WIFI wireless WLAN card and the WIFI card of multi-service router, and through starting NAT on multi-service router, the internal network will be subject to NAT conversion when accessing to the internet through $3 \mathrm{G}$, and this has ensured the internal private network safety.

The experimental teaching is not only the deepening and supplementation of theoretical teaching, it can also exert a very important role in cultivating students' to comprehensively utilize the learned knowledge, solve the actual problems, and deepen the understanding and application of network theoretical knowledge. Thus, we start from the reinforcement of laboratory construction, the normalization of experimental teaching link, and the reasonable setup of experimental contents, to reform the experimental teaching of computer network.

The computer network technology is a comprehensive inter-discipline integrating computer technology and communication technology, and it is a course with strong theoretical property, systematicness and practicalness; besides, new technologies have been constantly emerged. Under such condition, how to conduct well the teaching of computer network course, improve the teaching quality, and cultivate network talents possessing rich theoretical knowledge, higher analysis, design, development, management and application development skills for the society is an urgent research task.

"Internet + " has a higher demand for talents' manipulative ability, so it is requested to reinforce practical education, and integrate the various resources inside and outside of the campus Practical education is not only a teaching method, but also a teaching link. It takes the skill training as the main contents, the cultivation of practical innovation and entrepreneurship capacity as the objective, and the teachers' guidance and the students' active participation as the main teaching method, and it is an important channel for students to convert knowledge to capacity, and apply theory in practice. Thus, the reinforcement of practical education is an important link for cultivating the students' innovation and entrepreneurship capacity.

Practical teaching refers to the process for students to apply the learned principle knowledge to solve the actual computer system design issues, and it is also an important means to check the teaching effect. In various relevant courses, we adjust the original experimental system and experimental contents. The course experiments are regarded as the model or basis for the final comprehensive experiment, and this can not only consolidate the conceptual knowledge learned in the course, but also be used as an integral comprehensive experimental model, and it can realize the recursive evolution of experimental system. To improve the course design level, the contents of course design shall keep pace with the times, and be closely associated with actual production. The design content is based on the enterprise design development demand, and then changed to "learning by using" from "cramming education" through the sublimation and extraction of teachers; it can cultivate the students' capacity of using knowledge, and self-learning, improve the students' independent working capacity, and reinforce the learning interest. The framework of network experiment link we designed is as shown in Figure 1.

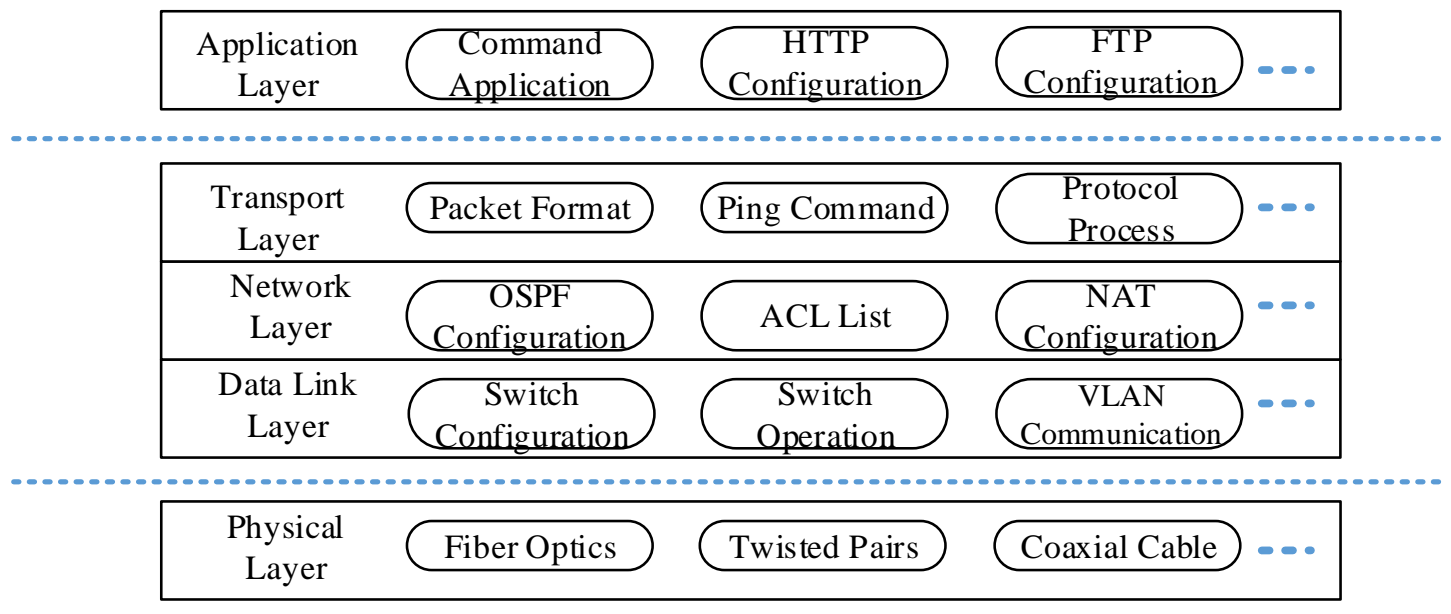

Fig. 1 System Architecture of the Practical Link

\section{CONCLUSION}

"Internet+" has integrated the knowledge of several industries, and this requests the changes in the teaching method, so as to adapt to the demand of students for innovation and entrepreneurship knowledge. The teaching method is the main factor restricting the innovation capacity development of students. The cultivation of innovative and entrepreneurial talents cannot be separated from reform and innovation, and then through the innovation of education concept, the comprehensive innovation of teaching contents, teaching mode and teaching technology can be promoted. The teaching mode must realize the transformation from the traditional knowledge teaching mode centered on teachers to the teaching mode of combining innovation and practice, implementing the interaction between teachers and students, learning while teaching, and taking the mobilization of students' autonomous learning, the stimulation of students' thirst for knowledge and creativity as the main objective. 


\section{ACKNOWLEDGEMENT}

Many thanks to the subsidy of Chongqing Higher Education and Teaching Reform (Project No: 173068), and the subsidy of Chongqing University of Posts and Telecommunications Education and Teaching Reform Research Project (Project No: XJG1513).

\section{REFERENCES}

[1] Wang Yingyun. Course Teaching Reform and Research of Computer Network Application Technology under the Era of Internet+[J]. Journal of Chifeng University (Natural Science Edition), 2016, 32(21): 230-231.

[2] Chen Xiyuan. Reform of Computer Network Teaching Courses in Colleges Based on the New Teaching Reform Background[J]. China New Telecommunications, 2017, (7): 131.

[3] Zhao Xiaojuan. Discussion about the Computer Network Teaching Course Reform in Universities under the New Teaching Reform Background [J]. PC Fan, 2017, (2):54.

[4] Yang Mingkun. How to Conduct Well the Computer Network Teaching Course Reform in Colleges under the Background of New Courses[J]. Digital World, 2017, (6): 140-141.

[5] Yu Shouxia, and Li Jing. Exploration on the New Teaching Mode of Public Computer Course in Colleges during the Era of "Internet+" $[\mathrm{J}]$. Talent Resources Development, 2017, (6): 117-118.

[6] Song Hongguang, Xu Dali, and Hou Chang. Computer Network Practical Teaching Reform Research under Internet[J]. Course Education Research, 2016, (36): 19-20. 